\title{
OIL POLLUTION OF THE SOUTHEASTERN BALTIC SEA BY SATELLITE REMOTE SENSING DATA AND IN-SITU MEASUREMENTS
}

\author{
Elena V. Bulycheva ${ }^{1}$, Aleksander V. Krek ${ }^{1,2}$, Andrey G. Kostianoy ${ }^{3,4,5}$, \\ Aleksander V. Semenov ${ }^{5}$, Aleksandar Joksimovich ${ }^{6}$ \\ ${ }^{1}$ Atlantic Branch of P.P. Shirshov Institute of Oceanology, Russian Academy of Sciences \\ Kaliningrad, Russia, Prospekt Mira 1 \\ E-mail: bulycheva.lena@gmail.com \\ ${ }^{2}$ Immanuel Kant Baltic Federal University \\ Kaliningrad, Russia, Aleksandra Nevskogo Str. 14, Build. 2 \\ E-mail:av_krek_ne@mail.ru \\ ${ }^{3}$ P.P. Shirshov Institute of Oceanology, Russian Academy of Sciences \\ Moscow, Russia, Nakhimovsky Pr. 36, \\ E-mail: kostianoy@gmail.com \\ ${ }^{4}$ GeoHydrodynamics and Environment Research, University of Liege \\ Liege, Belgium, Sart Tilman, B5 \\ E-mail: kostianoy@gmail.com \\ ${ }^{5}$ S.Yu. Witte Moscow University \\ Moscow, Russia, Second Kozhukhovsky Pr. 12, Build. 1 \\ E-mail: semen7777@gmail.com \\ ${ }^{6}$ Institute of Marine Biology, University of Montenegro \\ Kotor, Montenegro, P.Box 69 \\ E-mail:acojo@ac.me
}

\begin{abstract}
Results of operational satellite monitoring of oil pollution of the sea surface together with in-situ measurements of the oil products concentration in the water column for the first time allowed to establish relation between the surface pollution originated from ships, and the general characteristics of spatial and temporal distribution of oil products in the water column in the Southeastern Baltic Sea. Areas with heightened concentrations of oil products in the surface and bottom layers were determined for the study area. The main directions of the contamination propagation are agreed with the main direction of annual mean transport of substances in the Gdansk Basin.
\end{abstract}

Keywords: the Southeastern Baltic Sea, oil pollution, satellite monitoring, field measurements, geochemical barriers, D-6 oil platform

\section{Introduction}

The main sources of oil pollution of the sea are ships, seepages from the seabed, rivers runoff, municipal and industrial discharges, and the atmosphere (Nelson-Smith, 1977; Burger, 1997; Patin, 2001, 2008; Nemirovskaya, 2004, 2012, 2013; Kostianoy and Lavrova, 2014). Oil pollution of the seas and oceans fall into chronic pollution (permanent pollution in small portions due to anthropogenic impact or natural causes) or accidental pollution (a rare but usually severe contamination as a result of catastrophic oil spills from ships, oil platforms, and offshore pipelines). The relative proportions of each of the sources (or causes) of oil pollution vary by 10 to 100 times, which is explained by different methods of estimations, the specifics of different regions of the oceans and inland seas, as well as by various decades taken for the analysis. The largest portion (20-50\%) of the total pollution of the oceans by oil products is associated with maritime transport (Burger, 1997; Patin, 2008; Nemirovskaya, 2013; Kostianoy and Lavrova, 2014).

During the last decade the intensity of shipping in the Baltic Sea is constantly growing. The number of vessels and their size is increasing, and this trend will continue in the nearest future. This leads to an increase in the chronic oil pollution, as well as to an increasing risk of a large oil spill in the Baltic Sea (HELCOM, 2013; Kostianoy and Lavrova, 2014; Kostianoy et al., 2015). Since 2004, in the Russian sector 
of the Southeastern Baltic Sea there is an oil extraction from the oil field Kravtsovskoye (D-6) operated by LUKOIL-KMN, Ltd. what involves certain risks of oil pollution.

The basic physical, physicochemical, and biological processes in the sea are associated with the location of contacting and interacting mediums and phases of the matter, the so-called, geochemical barriers (Emelyanov, 1986, 1998). It is known that the most important natural geochemical barrier zones for the Russian sector in the Southeastern Baltic Sea, in the absence of major rivers, are the following boundaries: "sea - atmosphere", "water - bottom" and "the sea - shore". The most subjected to the anthropogenic impact part of the marine environment is the sea surface. The main gas exchange with the atmosphere takes place through it. The bottom sediments, in turn, are a permanent source of secondary pollution of the sea (Nemirovskaya, 2012, 2013). Therefore we will consider the spatial and temporal characteristics of the oil products distribution on the basic physicochemical barriers.

The aim of this paper is to compare the oil pollution on the sea surface derived from satellite observations and in-situ measurements of the oil products concentration in the surface and near-bottom layers of the sea water in the Southeastern Baltic.

\section{Data and Methods}

\subsection{Satellite observations}

Satellite monitoring of the Southeastern Baltic Sea surface is carried out from the beginning of oil extraction at the D-6 - from June 2004 (Kostianoy et al., 2006, 2015; Bulycheva and Kostianoy, 2011, 2014; Lavrova et al., 2014). The main purpose of satellite observations is to detect oil slicks at the sea surface. From 12 June 2004 to 31 December 2014 for the purpose of satellite monitoring the images from several satellites were received and analyzed: ENVISAT (European Space Agency - ESA) - 1143 ASAR images, RADARSAT-1 (Canadian Space Agency - CSA) - 298 SAR images, RADARSAT-2 (MacDonald, Dettwiler and Associates, Ltd. - MDA, Canada) - 343 SAR images, as well as satellites of the Italian Space Agency (ASI) Cosmo-SkyMED-1, -2, -3, -4 - 61 SAR images (Fig. 1).

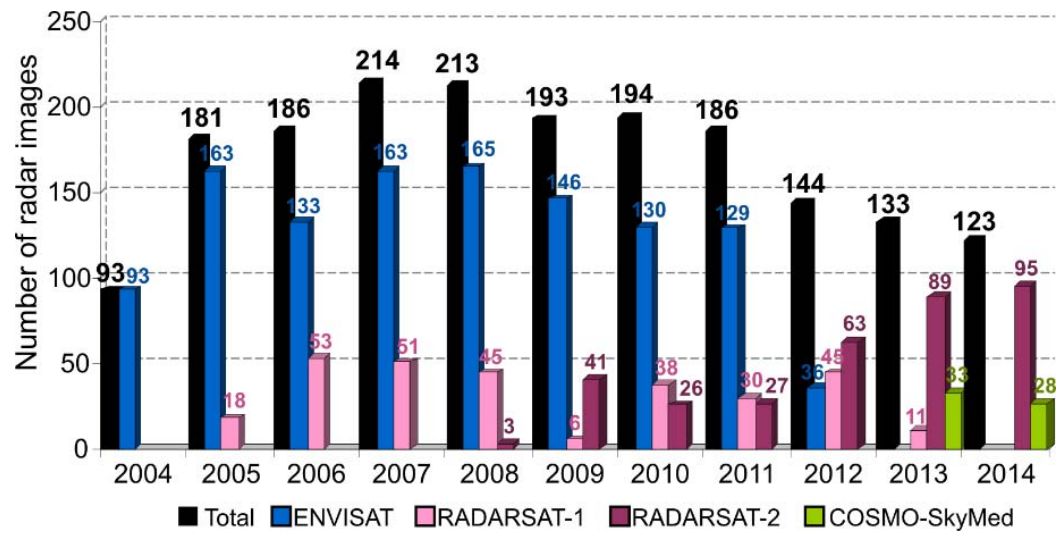

Figure 1. The number of SAR/ASAR images received from different satellites and analyzed (see Kostianoy et. al., 2015)

All these satellites are equipped with a synthetic aperture radar (SAR), which records the spatial variability of gravitational-capillary waves which are always present on the sea surface. The films of different origin, such as oil, biogenic, synthetic surfactants, as well as algal blooms, sea ice, and a number of hydrophysical and meteorological processes locally modify the surface roughness of the sea surface basically due to viscosity and form the smooth surface areas (slicks), which are captured by the SAR. The main advantages of the satellite SAR systems are the abilities to work in all weather conditions and independence on daylight. A limitation of the method is the condition that the near-water wind speed should be in the range of $2-10 \mathrm{~m} / \mathrm{s}$, otherwise radar images are not informative because of large areas of calm water in the sea (no roughness) at winds of $0-1 \mathrm{~m} / \mathrm{s}$ or at winds $>10 \mathrm{~m} / \mathrm{s}$ when breaking wind waves dominate in the formation of the sea roughness. The processed radar images were received from the Norwegian satellite operator - the Kongsberg Satellite Services (KSAT, Tromsø). The interval between the successive SAR images ranged from 12 to 72 hours. 


\subsection{Field measurements}

Concentrations of oil products in the sea water were obtained during the complex industrial environmental monitoring of the oil field Kravtsovskoye in 2003-2014 in the standard points of monitoring (Fig. 2). Sea water was sampled by plastic water sampler from the surface layer $(0.5-1.0 \mathrm{~m})$ and near-bottom layer (1.0 $\mathrm{m}$ from the bottom), as well as from the intermediate layers $(10,30,50$ and $70 \mathrm{~m})$ depending on the depth at the point. Concentrations of oil products obtained during one survey at close points around the D-6 platform (the distance between points vary from 250 to $1000 \mathrm{~m}$ ) were averaged to a single value. Concentrations of oil products in sea water were determined in the Federal State Unitary Enterprise Atlantic Research Institute for Fishery and Oceanography (Kaliningrad) by the fluorimetric method on the analyzer of liquids "Fluorat-02" (Document, 1998a, b).

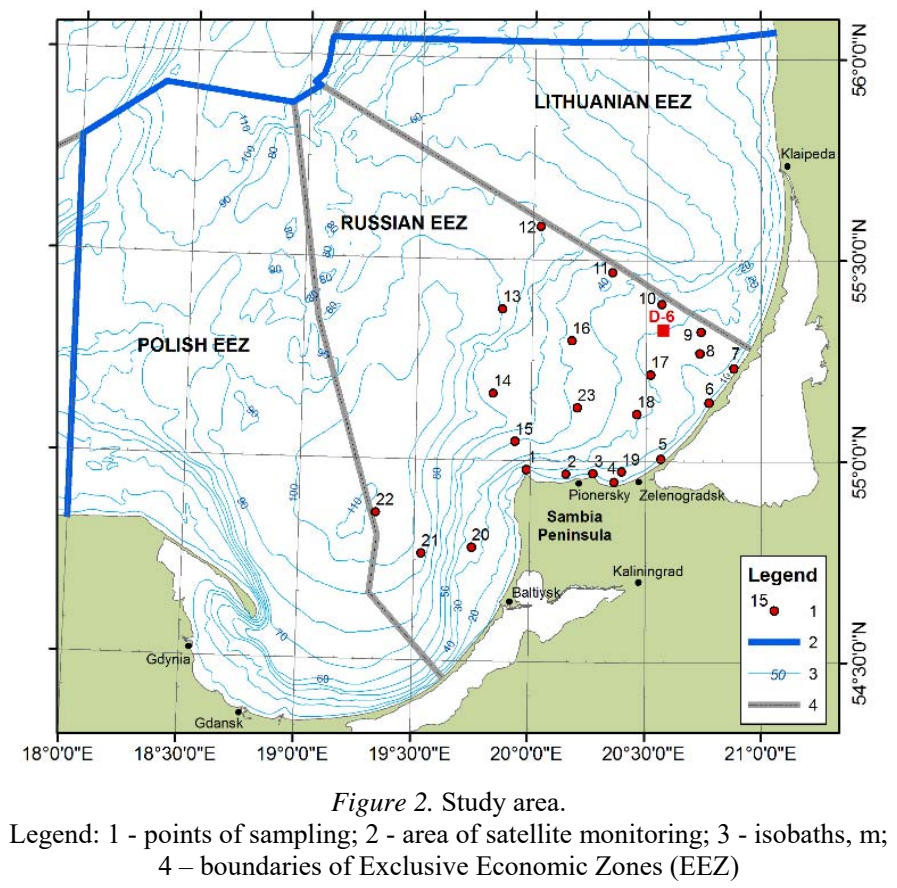

\section{Results of satellite observations}

From 12 June 2004 to 31 December 20141845 satellite radar images were received and analyzed, and 1193 oil spills were detected. 616 oil slicks were located within the study area (Fig. 3). The most of the detected oil spills were observed in spring and summer (Fig. 4, Fig. 5) what could be explained by moderate near-water wind speed prevailed in these seasons, and oil slicks are well identified on the radar images. In autumn and winter time strong winds dominate in the region, and the SAR method does not work well (Bulycheva and Kostianoy, 2014). The study of seasonal variability of oil pollution was made in accordance with hydrological seasons specific for the Southeastern Baltic Sea. In particular, in the Gdansk Basin the period from January to March is taken as winter, April-June - is spring, July-September - is summer, and October-December - is autumn (Bernikova et al., 2007). About $80 \%$ of all oil spills were detected from April to September, what corresponds to $86 \%$ of the total area of oil spills detected in the area of satellite monitoring.

According to satellite radar imagery, the most polluted waters in the Southeastern Baltic Sea are the areas of shipping routes, anchorages to the west of the Sambia Peninsula, and the approaches to the port of Baltiysk. The sources of oil pollution northward of the port of Pionersky are small fishing ships (Bulycheva et al., 2014). The combined analysis of the shapes and concentration of oil spills with the location of the main navigation routes based on the Automatic Identification System (AIS) for the Baltic Sea (Fig. 6) led us to a conclusion that the main sources of oil pollution are different ships (Kostianoy and Lavrova, 2014; Bulycheva and Kostianoy, 2014; Kostianoy et al., 2015). The detailed examination of the Fig. 6 reveals that the oil spills are slightly displaced from the shipping routes - the places of their potential origin. This is explained by the peculiarities of hydrometeorological regime in the Southeastern Baltic Sea and general scheme of water circulation in the Gdansk Basin (Meier, 2007). Another reason is the pollution from small ships which are not equipped with the AIS (Bulycheva et al., 2014). 


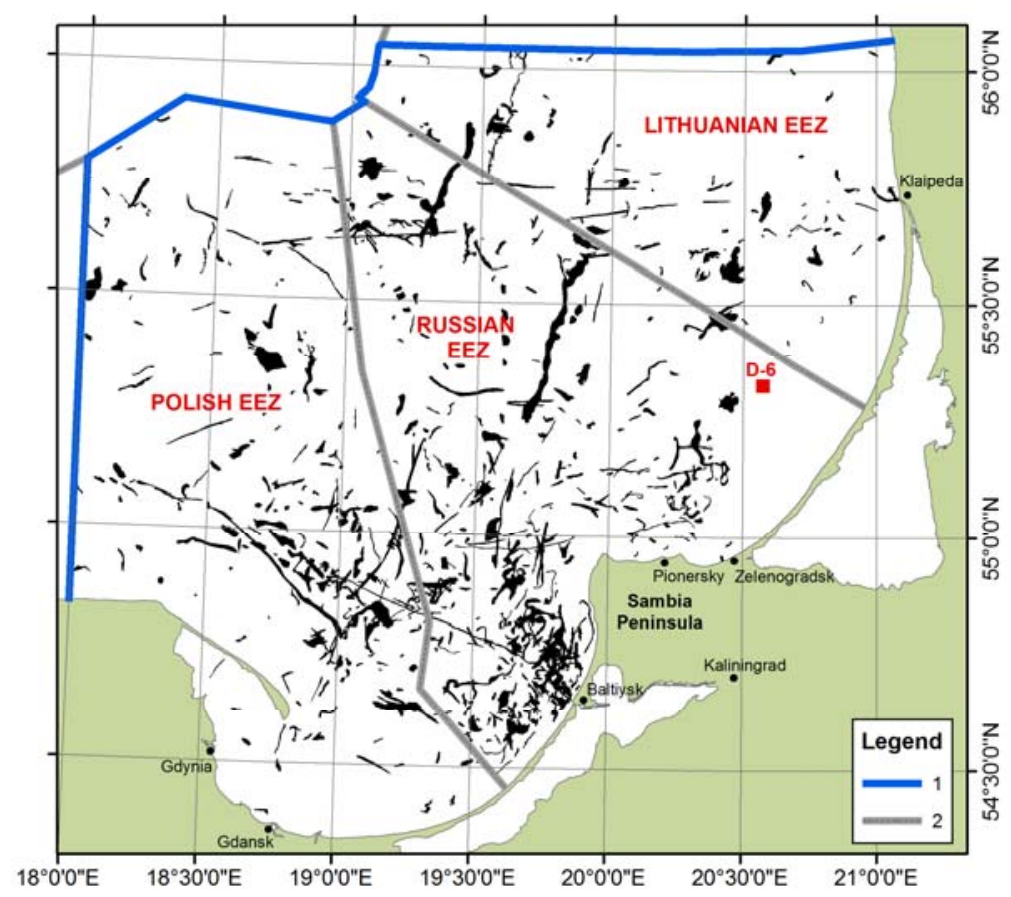

Figure. 3. Summary map of oil spill detected in the result of radar images analysis from 12.06.2004 to 31.12.2014 Legend: 1 - Area of satellite monitoring; 2 - boundaries of Exclusive Economic Zones (EEZ). The real shapes of oil spills are presented

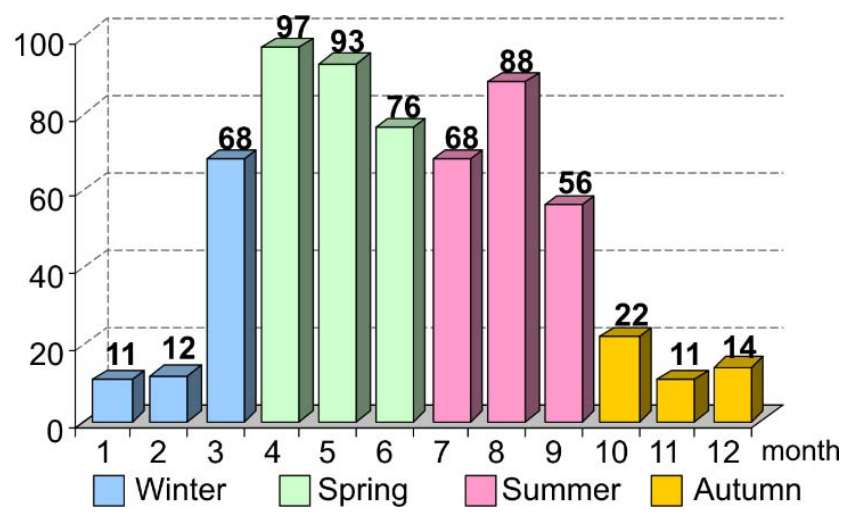

Figure 4. Seasonal variability of number of detected oil spills from 12.06.2004 to 31.12.2014

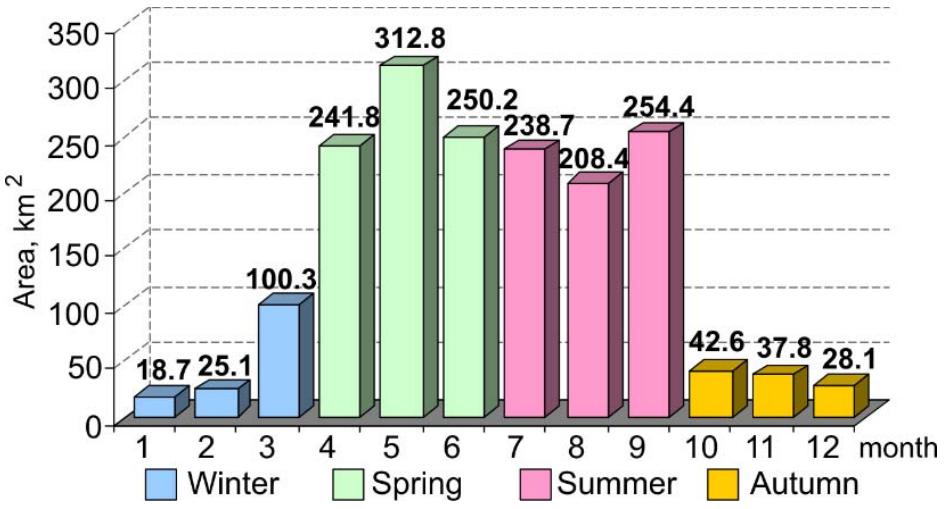

Figure 5. Seasonal variability of oil pollution area observed by satellite radar data from 12.06.2004 to 31.12.2014 


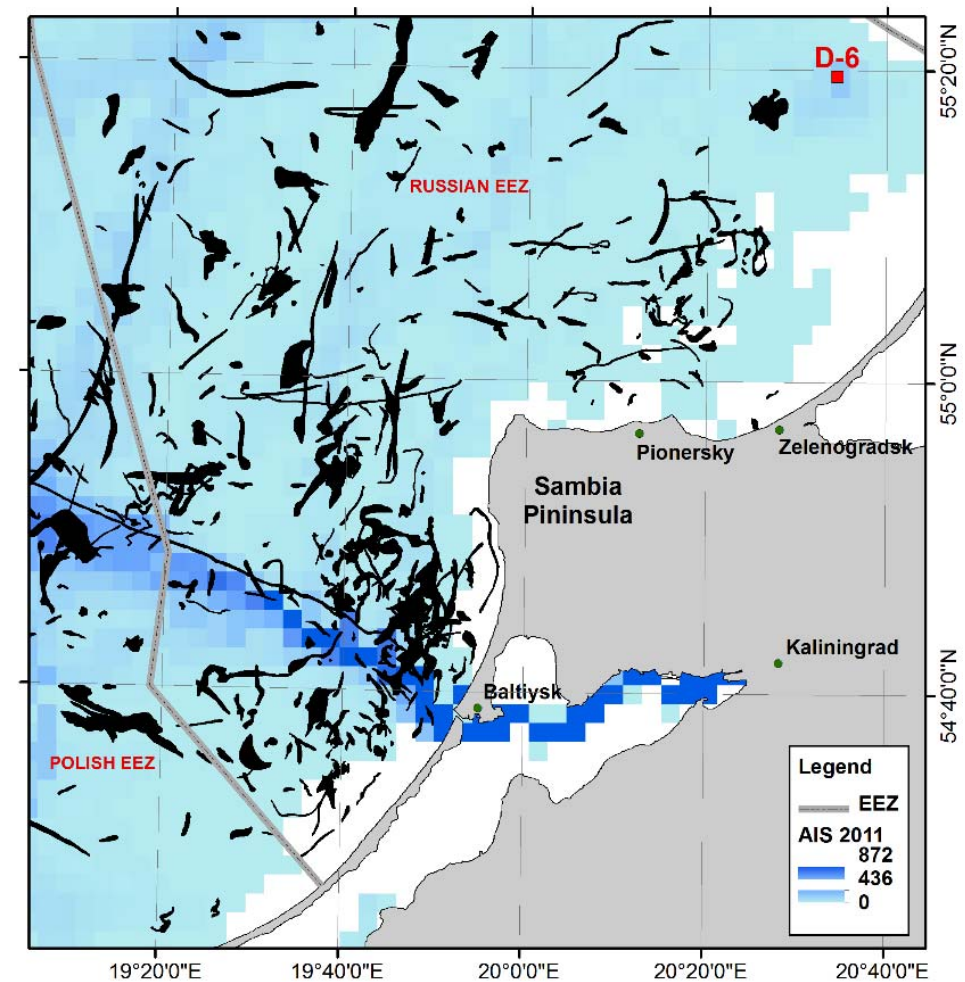

Figure 6. Density of the AIS signals according to (HELCOM, 2011) and oil spills detected from 12 June 2004 to 31 December 2014

The interannual tendency to reduction of oil pollution in the Southeastern Baltic Sea was observed from 2006 to 2011 (Fig. 7) (Bulycheva and Kostianoy, 2014). According to HELCOM, a similar trend was observed for the whole Baltic Sea in 1988-2011 (Kostianoy and Lavrova, 2014). In 2012, there was a sharp increase in the number of detected oil spills and as a result, the total area of oil pollution. In 2013, with a relatively small number of oil spills we observed a high total area of oil pollution what could be explained by a huge oil spill detected on 13 September 2013 (Bulycheva and Kostianoy, 2014).

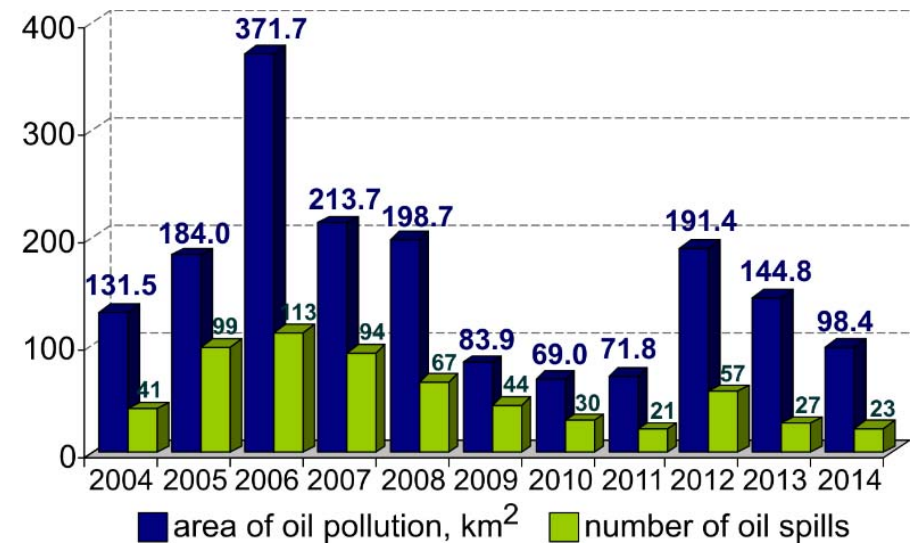

Figure 7. Interannual variability of area of oil pollution and the number of oil spills in the Southeastern Baltic Sea

\section{Results of in-situ observations}

In the interannual variability, the maximum concentrations of oil products in the surface and nearbottom layers were observed in 2003 (Fig. 8), what was associated with the accident of the Chinese tanker "Fu Shanghai" in the Southwestern part of the Baltic Sea, and the specific hydrometeorological conditions at that time (Nemirovskaya, 2012 ). Therefore, the data for 2003 were not taken into account for further analysis. 


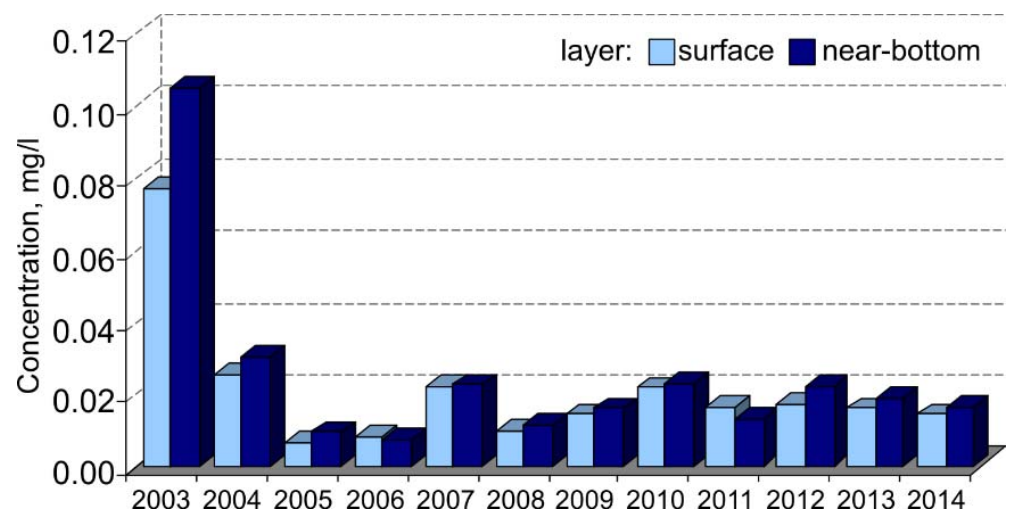

Figure 8. Interannual variability of the averaged concentration of oil products in the surface and near-bottom layers of the Southeastern Baltic Sea

Vertical distribution of the concentration of oil products and suspended matter in the water column were likely similar at different points. It is known that the gradient of density layer is the boundary separating the inflow of oil products from the sea surface, and the secondary pollution from the bottom sediments (Afanasyeva et al., 1990; Emelyanov, 1998). The highest values of oil products concentrations were observed at the sea surface, while the secondary maximum - above the main halocline at the depth of about $70 \mathrm{~m}$. Therefore, at the deepwater points ( $>70 \mathrm{~m}$ deep) instead of oil concentration in the near-bottom layer, the concentration of oil products above halocline were used.

The average and maximum concentrations of oil products in the surface layer were slightly higher than similar concentrations in the near-bottom and intermediate layers (Table 1), what may indicate that the main source of oil products in the water column is the sea surface. A similar vertical distribution of the oil products concentration in different seasons was observed. Its maximum value was detected in spring and the minimum - in the autumn (Table 2). In all cases, the average concentration did not exceed the maximum permissible concentration $=0.05 \mathrm{mg} / \mathrm{l}$ (Order of the Federal Fisheries Agency, 2010).

Table 1. Concentrations of oil products in the Russian sector of the Southeastern Baltic Sea

\begin{tabular}{|c|c|c|c|}
\hline \multirow{2}{*}{ Layer } & \multicolumn{3}{|c|}{ Concentration, mg/l } \\
\cline { 2 - 4 } & min & average & max \\
\hline Surface & 0.001 & $0.018 \pm 0.021$ & 0.208 \\
\hline Near-bottom & 0.001 & $0.016 \pm 0.018$ & 0.183 \\
\hline Water column & 0.001 & $0.016 \pm 0.018$ & 0.136 \\
\hline
\end{tabular}

Table 2. Seasonal variability of concentrations of oil products in the surface and near-bottom layers in the Southeastern Baltic Sea

\begin{tabular}{|c|c|c|}
\hline Season & Surface layer, $\mathbf{~ m g / l}$ & Near-bottom layer, $\mathbf{~ m g / l}$ \\
\hline Winter & $0.016 \pm 0.020$ & $0.015 \pm 0.017$ \\
\hline Spring & $0.027 \pm 0.032$ & $0.019 \pm 0.022$ \\
\hline Summer & $0.019 \pm 0.017$ & $0.017 \pm 0.017$ \\
\hline Autumn & $0.014 \pm 0.011$ & $0.012 \pm 0.009$ \\
\hline
\end{tabular}

In shallow coastal waters, near D-6 oil platform (monthly measurements in 2011-2014) the maximum average concentration of oil products were recorded in the surface layer $(0.026 \pm 0.014 \mathrm{mg} / \mathrm{l})$ with the subsequent decrease of the concentration to the bottom $(0.020 \pm 0.011 \mathrm{mg} / \mathrm{l}$ - in the water column and $0.019 \pm 0.009 \mathrm{mg} / \mathrm{l}$ - near the bottom). In general, areas of heightened concentrations of oil products in the surface and near-bottom layers are consistent with the main direction of transport of matter from the area of maximum accumulation of oil spills detected from satellite observations (Fig. 9, Fig. 10).

In the surface and near-bottom layers, areas with heightened and low concentrations of oil products were determined (Fig. 9, Fig. 10). At the sea surface, heightened concentrations were observed in waters adjacent to the Sambia Peninsula (Fig. 9). The maximum average concentrations of oil products were recorded at points 2 and 20 and amounted to $0.044 \pm 0.046 \mathrm{mg} / \mathrm{l}$ and $0.035 \pm 0.023 \mathrm{mg} / \mathrm{l}$, respectively. A small exceeding of the concentration of oil products was noticed around the D-6 oil platform in the surface and near-bottom layers (Fig. 9, Fig. 10). 


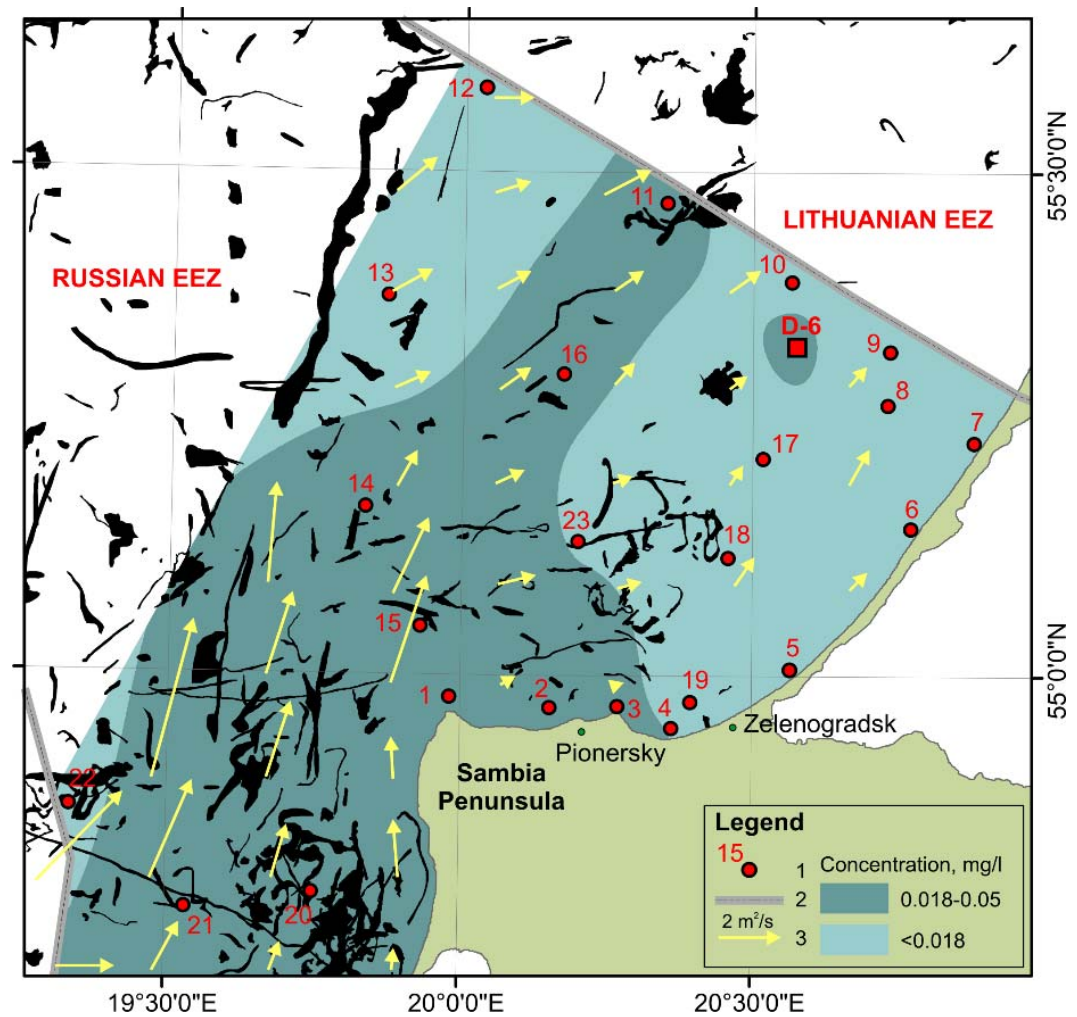

Figure 9. Spatial distribution of oil spills, mean annual concentration of oil products in the surface layer and the mean transport of matter in the surface layer of the Southeastern Baltic Sea.

Legend: 1 - points of water sampling; 2 - EEZ; 3 - transport of matter in the surface layer according to (Meier, 2007)

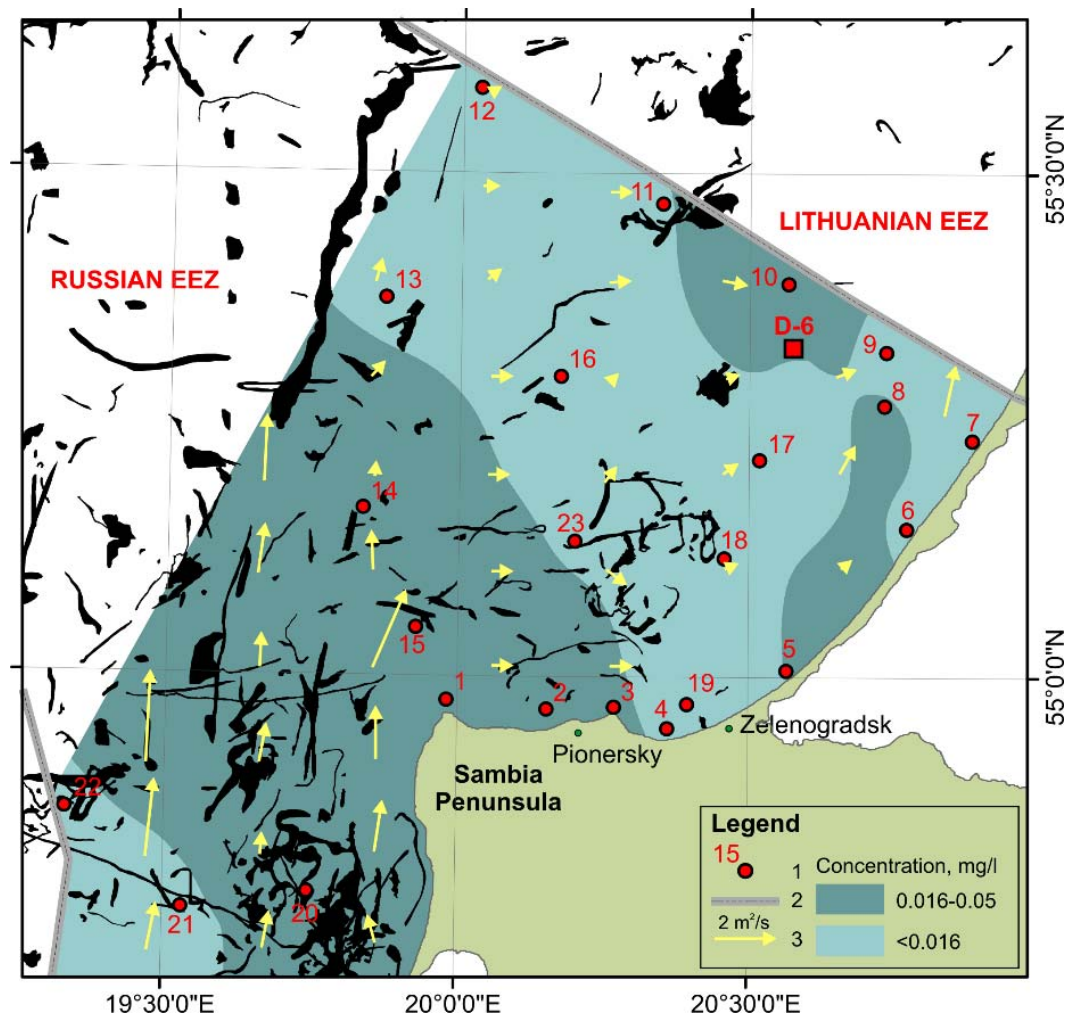

Figure 10. Spatial distribution of oil spills, mean annual concentration of oil products in the near-bottom layer and the mean transport of matter in the near-bottom layer of the Southeastern Baltic Sea.

Legend: 1 - points of water sampling; 2 - EEZ; 3 - transport of matter in the near-bottom layer according to (Meier, 2007) 
Taking into account the system of currents in the Gdansk Basin (Meier, 2007) and the average direction of the near-water wind, directed to the North-East (Stont, 2014), there are favorable conditions for the transfer of matter from the main area of contamination to the North and North-East (see Fig. 9). In the particular cases, around the Taran Cape, there is a sufficiently complex system of currents enveloping the cape and propagating along the northern coast of the Kaliningrad Region (Meier, 2007).

In the near-bottom layer (or above the halocline), in general, the area of heightened concentrations of oil products coincides with the similar area on the sea surface layer (see Fig. 9, Fig. 10). The area around points D-6, 10, and 11 is stand out, what could be explained by the peculiarities of the circulation described above, as well as by activities on D-6 oil platform.

Elevation in concentration of oil products at points 5 and 8 (see Fig. 10) is likely a result of a transport of pollution from the area of the port of Pionersky.

\section{Conclusions}

For the first time, the comparison of the results of satellite monitoring of oil pollution at the sea surface in the Southeastern Baltic Sea and in-situ measurements of oil products concentration in the water column was carried out. Overlapping the results of satellite and field observations together with the peculiarities of the general water circulation allowed to trace the main transfer of oil contamination. The main source of oil pollution of the waters around the Sambia Peninsula is the main shipping routes westward from Sambia Peninsula. The main transport of oil pollution from the waters westward of the Sambia Peninsula occurs in the northern and north-eastern directions, both in the surface and the near-bottom layers.

Low concentrations of oil products in the seawater (below the maximum permissible concentration) suggest that the oil spills observed on the radar imagery are not catastrophic and do not affect the ecological situation in the Southeastern Baltic Sea. This is also supported by the fact that despite the change in the number of oil spills and the total surface of oil pollution in five times in the period between 2004 and 2014, the concentration of oil products in the seawater remains more or less stable and does not follow the interannual variability of the detected oil spills. This means that natural physical and biogeochemical processes in the sea are still capable to "consume" the observed incoming volume of the anthropogenic oil pollution.

\section{Acknowledgements}

The authors would like to thank LUKOIL-KMN, Ltd. for providing of satellite radar imagery and insitu data from ship surveys. E.V. Bulycheva and A.G. Kostianoy conducted a study of oil pollution using satellite data in the framework and with a support of the Russian Science Foundation Project N 14-50-00095. A.V. Krek was engaged in the analysis of concentration of oil products in sea water obtained by the ship's measurements in the framework and with a support of the Russian Science Foundation Project N 14-37-00047.

\section{References}

1. Afanasyeva, N.A., Geydarov, F.A., Zatuchnaya, B.M., and Ivanova T.A. (1990) The role of suspended matter in the redistribution of petroleum hydrocarbons in the marine environment (on the example of the North Atlantic). In: Oceanographic aspects of the preservation of seas and oceans from chemical pollution. Moscow, Gidrometeoizdat, 216-219 (in Russian).

2. Bernikova, T.A., Dubravin, V.F., Nagornova, N.N., and Stont, Zh.I. (2007) The climatic seasons of the Southern Baltic. Proc. V International scientific conference "Innovations in science and education - 2007". Kaliningrad, Kaliningrad State Technical University, Part 1, 53-55 (in Russian).

3. Bulycheva, E.V. and Kostianoy, A.G. (2011) Results of the satellite monitoring of oil pollution in the Southeastern Baltic Sea in 2006-2009. Modern problems of remote sensing of the Earth from space, V8, N 2, 74-83 (in Russian).

4. Bulycheva, E.V. and Kostianoy, A.G. (2014) Results of satellite monitoring of the sea surface oil pollution in the Southeastern Baltic Sea in 2004-2013. Modern problems of remote sensing of the Earth from space, V11, N 4, 111-126 (in Russian).

5. Bulycheva, E., Kuzmenko, I., and Sivkov, V. (2014) Annual sea surface oil pollution of the southeastern part of the Baltic Sea by satellite data for 2006-2013. Baltica, V27, Special Issue, 9-14.

6. Burger, J. (1997) Oil spills. Rutgers University Press. New Brunswick. 262 pp.

7. Document (1998a) PND F 14.1:2:4.128-98 Quantitative chemical analysis of water. Methods of measurement of the mass concentration of oil in the samples of natural, drinking, waste waters by the fluorimetric method on the analyzer of a liquid "Fluorat-02." (in Russian). 
8. Document (1998b) PND F 16.1:2.21-98 Quantitative chemical analysis of soil. Methods of measurement of the mass fraction of oil in the samples of soil and ground by the fluorimetric method using the liquid analyzer "Fluorat-02." (in Russian).

9. Emelyanov, E.M. (1998) The barrier zones in the ocean. Sedimentation and mineralization, geoecology. Kaliningrad, Yantarny skaz, 416 pp. (in Russian).

10. HELCOM (2013) Illegal discharges observed during aerial surveillance 2013. Source: http://www.helcom.fi/Lists/Publications/HELCOM/report/202013.pdf

11. Kostianoy, A.G., Bulycheva, E.V., Semenov, A.V., and Krainyukov, A.V. (2015) Satellite monitoring systems for shipping, and offshore oil and gas industry in the Baltic Sea. Transport and Telecommunication, V16, N2, 117-126.

12. Kostianoy, A.G. and Lavrova, O.Yu. (Eds.) (2014) Oil pollution in the Baltic Sea. Springer-Verlag, Berlin, Heidelberg, New York. V27. 268 pp.

13. Kostianoy, A.G., Litovchenko, K.Ts., Lavrova, O.Yu., Mityagina, M.I., Bocharova, T.Yu., Lebedev, S.A., Stanichny, S.V., Soloviev, D.M., Sirota, A.M., and Pichuzhkina, O.E. (2006) Operational satellite monitoring of oil spill pollution in the southeastern Baltic Sea: 18 months experience. Environmental Research, Engineering and Management, N4(38), 70-77.

14. Lavrova, O.Yu., Mityagina, M.I., Kostianoy, A.G., and Semenov, A.V. (2014) Oil pollution in the southeastern Baltic Sea in 2009-2011. Transport and Telecommunication, V15, N4, 322-331.

15. Lobkovsky, L.I., Levchenko D.G., Leonov A.V., and Ambrosimov A.K. (2005) Geo-environmental monitoring of oil and gas marine areas. Moscow, Nauka, 326 pp. (in Russian).

16. Meier, H.E.M. (2007) Modelling the pathways and ages of inflowing salt- and freshwater in the Baltic Sea. Estuarine, Coastal and Shelf Science, N74, 610-627.

17. Nelson-Smith, A. (1977) Oil and ecology of the sea. Moscow, Progress, 298 pp. (in Russian).

18. Nemirovskaya, I.A. (2004) The hydrocarbons in the ocean (the snow - ice - water - suspended matter - bottom sediments). Moscow, Nauchny mir, 328 pp. (in Russian).

19. Nemirovskaya, I.A. (2012) Petroleum hydrocarbons. In: Oil and the environment of the Kaliningrad Region. V2: The Sea (Eds.) V.V. Sivkov, Yu.S. Kadzhoyan, O.E. Pichuzhkina, V.N. Feldman. Kaliningrad, Terra Baltica, 152-173 (in Russian).

20. Nemirovskaya, I.A. (2013) Oil in the ocean. Pollution and natural flows. Moscow, Nauchny mir, 428 pp. (in Russian).

21. Order of the Federal Fisheries Agency (2010) "On approval of standards for water quality of fishery water bodies, including the maximum permissible concentrations of harmful substances in the waters of fishery water bodies» N20, 18.01.2010 (in Russian).

22. Patin, S.A. (2001) Oil and ecology of continental shelf. Moscow, VNIRO, 340 pp. (in Russian).

23. Patin, S.A. (2008) Oil spills and their impact on the marine environment and aquatic resources. Moscow, VNIRO, 507 pp. (in Russian).

24. Stont, Zh.I. (2014) Modern trends in variability of hydrometeorological parameters in the southeastern part of the Baltic Sea and their reflection in the coastal processes. Synopsis of the thesis on geography sciences. Kaliningrad, Atlantic Branch of P.P. Shirshov Institute of Oceanology, 23 pp. (in Russian). 